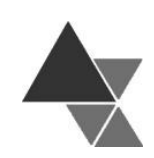

\title{
Adequação nutricional de cardápios do almoço de uma empresa do ramo hoteleiro inscrita no Programa de Alimentação do Trabalhador
}

\author{
Bruna Merten Padilha', Thaysa Barbosa Cavalcante Brandão², Fernanda Regina \\ Amorim Albuquerque ${ }^{3}$, Marília Ferreira Lima $^{4}$ e Raissa Milena Silva Freitas ${ }^{5}$
}

Objetivou-se avaliar a adequação nutricional de cardápios do almoço de uma empresa do ramo hoteleiro inscrita no Programa de Alimentação do Trabalhador (PAT) aos parâmetros nutricionais estabelecidos pela legislação do programa. Estudo descritivo, realizado em 2019, a partir da análise dos cardápios cíclicos de sete dias do almoço servidos aos funcionários de uma empresa hoteleira cadastrada no PAT, situada em Maceió, Alagoas. Calculou-se a composição nutricional da refeição por meio da Tabela Brasileira de Composição de Alimentos, utilizando-se os ingredientes e os valores per capita descritos nas fichas técnicas de preparo da empresa. Compararam-se os valores obtidos aos parâmetros nutricionais estabelecidos na Portaria Interministerial no 66/2006. Os dados foram tabulados e analisados no Epi-Info 6.04. O valor energético dos cardápios variou entre 726,4 kcal e 1196,2 kcal. Houve inadequação de proteínas, fibras e NdPCal\% aos parâmetros nutricionais e $100 \%$ de adequação do percentual de gorduras saturadas. Constatou-se a oferta diária de frutas, legumes e verduras em todos os cardápios. Considerando que os parâmetros propostos visam à promoção da saúde do trabalhador, torna-se necessário que a empresa adeque os cardápios ofertados, principalmente no que diz respeito a proteínas e fibras.

Palavras-chave: Planejamento de cardápio; Programas e políticas de nutrição e alimentação; Serviços de alimentação.

\section{Nutritional adequacy of the lunch menu of a hotel company registred in the Worker Feeding Program}

The objective was to evaluate the nutritional adequacy of the lunch menu of a hotel company registred in the Worker Feeding Program (WFP) to the nutritional parameters established by the program legislation. Descriptive study, carried out in 2019, based on the analysis of the seven-day lunch menu served to employees of a hotel company registered in the WFP, located in Maceió, Alagoas. The nutritional composition of the meal was calculated using the Brazilian Food Composition Table, using the ingredients and per capita described in the company's technical preparation sheets. The values obtained were compared to the nutritional parameters established in Interministerial Ordinance No. 66/2006. The data were tabulated and analyzed using Epi-Info 6.04. The energy value of the menus varied between $726.4 \mathrm{kcal}$ and $1196.2 \mathrm{kcal}$. There was no adequacy of proteins, fibers and $\mathrm{NdPCal} \%$ to the nutritional parameters and 100\% adequacy of the percentage of saturated fats. The

${ }^{1}$ Doutora em Nutrição. Professora da Universidade Federal de Alagoas no curso de Nutrição, na área de Nutrição em Alimentação Coletiva. Endereço para correspondência: Av. Lourival Melo Mota, S/N - Tabuleiro do Martins, Maceió - AL, 57072-900. Universidade Federal de Alagoas. Faculdade de Nutrição. Sala 212. Tel.: (82) 99997-1427. E-mail: bruna48@hotmail.com. ID ORCID: https://orcid.org/0000-0001-7594-2578.

2 Doutora em Serviço social. Professora da Universidade Federal de Alagoas no curso de Nutrição, na área de Nutrição em Alimentação Coletiva. E-mail: thaysabcb@hotmail.com. ID ORCID: https://orcid.org/0000-0002-0153- 1044.

${ }_{3}^{3}$ Nutricionista. E-mail. fernanda.amorimra@gmail.com. ID ORCID: https://orcid.org/0000-0003-3823-346X.

${ }^{4}$ Nutricionista. E-mail: mariliafrlima@gmail.com. ID ORCID: https://orcid.org/0000-0003-0246- 5963.

${ }^{5}$ Nutricionista. Mestranda em Nutrição pela Universidade Federal de Alagoas. E-mail: raissamilena.freitas@gmail.com. ID ORCID: https://orcid.org/0000-0002-7376- 5704. 
daily supply of fruits and vegetables was found in all menus. Considering that the proposed parameters are aimed at promoting worker health, it is necessary for the company to adapt the menus offered, especially with regard to proteins and fibers.

Keywords: Menu planning; Nutrition programs and policies; Food services.

Submetido em: 06/06/2020

Aceito em: 13/04/2021

\section{INTRODUÇÃO}

O Programa de Alimentação do Trabalhador (PAT) é um programa governamental de complementação alimentar, que busca estimular o empregador a fornecer refeições nutricionalmente adequadas aos trabalhadores, por meio da concessão de incentivos fiscais ${ }^{[1]}$. Isso promove melhoria das condições nutricionais e da qualidade de vida dos trabalhadores, promovendo saúde e bem estar, e auxilia na prevenção de doenças relacionadas à alimentação e à nutrição[2].

Em virtude do atual cenário epidemiológico da população adulta brasileira, em que se evidencia o aumento das doenças crônicas não transmissíveis ${ }^{[3]}$, o cumprimento das normas referentes aos parâmetros nutricionais tratados na Portaria Interministerial no 66/2006 consiste numa importante estratégia para promover a alimentação saudável e a saúde do trabalhador, cabendo a um profissional legalmente habilitado em nutrição a responsabilidade técnica do programa e o planejamento das refeições que serão ofertadas ${ }^{[1]}$.

Apesar dos reconhecidos benefícios, na prática, o PAT enfrenta dificuldades para a sua execução, em decorrência de inúmeros fatores, dentre os quais, fragilidades dentro da própria empresa beneficiária, marcadas pelo vago conhecimento sobre o programa[4], e pela falta de ações sobre avaliação da qualidade da refeição, no que diz respeito a sua segurança microbiológica e adequação nutricional.

Portanto, para que o PAT possa atingir seu objetivo, o monitoramento constante torna-se necessário. Considerando-se que a oferta de refeições é o eixo básico do programa, deve-se averiguar se o planejamento dos cardápios se encontra adequado. Frente ao exposto, objetivouse avaliar a adequação nutricional de cardápios do almoço de uma empresa do ramo hoteleiro inscrita no Programa de Alimentação do Trabalhador aos parâmetros nutricionais estabelecidos pela legislação do programa.

\section{METODOLOGIA}

Trata-se de um estudo descritivo realizado, em outubro de 2019, a partir da análise dos cardápios do almoço servido aos funcionários de uma empresa hoteleira cadastrada no PAT, situada em Maceió, Alagoas, que foi selecionada por conveniência. Essa empresa é de médio porte e atua na modalidade de autogestão, com serviço de distribuição do tipo selfservice, produzindo cerca de 80 refeições para o almoço. As atividades dos comensais são consideradas de intensidade leve a moderada, pois as tarefas desempenhadas pelos funcionários do hotel não exigem grande mobilidade e/ou força física.

Os cardápios ofertados são cíclicos, se repetem semanalmente e são elaborados pelo nutricionista responsável técnico. Apresentam características de um cardápio do tipo médio, sendo constituídos por dois tipos de salada, duas a três opções de pratos proteicos, arroz e feijão como acompanhamentos, um tipo de guarnição, sobremesa (fruta) e suco.

A composição nutricional dos cardápios foi calculada no programa Diet Box 2.0, utilizando-se como referência a composição centesimal dos alimentos da Tabela de Composição de Alimentos ${ }^{[5]}$, de acordo com o peso líquido em gramas per capita de cada ingrediente utilizado nas preparações que compõem os cardápios, seguindo as informações dispostas nas fichas técnicas de preparo 
disponibilizadas pela empresa. Foram estimados valor energético total (VET) (kcal), carboidrato (\%), proteína $(\%)$, gordura total $(\%)$, gordura saturada $(\%)$, fibras (g), sódio (mg) e percentual protéicocalórico (NdPCal\%), o qual foi determinado com base na fórmula $\mathrm{NdPCal} \%=\{[$ (proteína ingerida $\mathrm{x}$ NPU) x 4] x 100\}/VET, considerando o NPU (utilização proteica líquida) a quantidade de proteína da dieta, corrigida em função da sua qualidade.

Verificou-se a adequação dos cardápios aos parâmetros nutricionais descritos na Portaria Interministerial no 66/2006[1], a qual prevê para uma dieta de $2000 \mathrm{kcal}$, que o almoço deve conter $60 \%$ de carboidratos, $15 \%$ de proteínas, $25 \%$ de gorduras totais, quantidade inferior a $10 \%$ de gorduras saturadas, 7-10g de fibras, 720-960 mg de sódio, $\mathrm{NdPCal} \%$ de 6 a 10\% e VET entre $600-800 \mathrm{kcal}$, podendo haver acréscimo de $20 \%$ do VET diário (400 kcal). Avaliou-se também se os cardápios ofertavam, pelo menos, uma porção de frutas e uma porção de legumes ou verduras na refeição principal do almoço[1].
Os dados referentes aos 7 dias dos cardápios da refeição do almoço foram tabulados e analisados no Epi-Info 6.04 e demonstrados através das medidas de média aritmética simples e desviopadrão. Os valores que estiveram dentro da margem diária prevista pela Portaria Interministerial $\mathrm{n}^{\circ}$ 66/2006[1], foram considerados adequados. Em contrapartida, aqueles que excederam ou escassearam os valores previstos foram pontuados como inadequados. Contabilizou-se o número e percentual de dias de adequação nutricional. O estudo foi realizado com o consentimento da empresa e sua identificação foi mantida em sigilo.

\section{RESULTADOS}

A composição nutricional dos sete cardápios do almoço está apresentada na Tabela 1 . Identificouse uma variação de VET entre $726,4 \mathrm{kcal}$ a 1196,2 $\mathrm{kcal}$. O domingo e a quarta-feira foram os dias que apresentaram os cardápios de menor e maior valor calórico, respectivamente.

Tabela 1 - Composição nutricional dos sete cardápios do almoço de uma empresa do ramo hoteleiro inscrita no Programa de Alimentação do Trabalhador (PAT), 2019.

\begin{tabular}{lcccccccc}
\hline $\begin{array}{l}\text { Component } \\
\text { e analisado }\end{array}$ & Segunda & Terça & Quarta & Quinta & Sexta & Sábado & Domingo & Média \pm \\
DP semanal \\
\hline VET (kcal) & 844,7 & 856,7 & 1196,2 & 802,1 & 815,8 & 767,0 & 726,4 & $858,4 \pm 74,3$ \\
Cho (\%) & 60,9 & 58,3 & 54,0 & 63,1 & 69,0 & 66,5 & 57,3 & $61,3 \pm 12,8$ \\
Proteínas & 23,9 & 18,2 & 21,0 & 18,7 & 19,2 & 20,9 & 22,3 & $20,6 \pm 8,4$ \\
(\%) & 16,6 & 25,4 & 27,0 & 19,2 & 14,1 & 17,9 & 20,9 & $20,2 \pm 4,3$ \\
GT (\%) & 6,0 & 6,9 & 7,7 & 6,1 & 6,2 & 6,6 & 6,8 & $6,6 \pm 1,6$ \\
GSat (\%) & 1223,6 & 1143,7 & 777,3 & 1127,1 & 951,1 & 562,6 & 1214,7 & $1000,0 \pm 192$, \\
Sódio (mg) & 14,7 & 18,5 & 19,9 & 14,9 & 20,7 & 17,6 & 14,7 & $17,3 \pm 3,1$ \\
Fibras (g) & 15,4 & 11,5 & 12,8 & 11,8 & 12,1 & 13,5 & 14,4 & $13,1 \pm 5,9$ \\
NdPCal (\%)
\end{tabular}

VET - valor energético total, Cho - carboidratos; GT - gorduras totais, GSat - gorduras saturadas, NdPCal percentual protéico-calórico, DP - desvio-padrão.

Os carboidratos foram os nutrientes que apresentaram maior contribuição energética, seguidos das proteínas e, por último, dos lipídios. $\mathrm{O}$ percentual de gorduras saturadas foi inferior a $10 \%$ em todos os dias da semana. O quantitativo de sódio esteve acima dos parâmetros estabelecidos pelo PAT, na maioria dos cardápios, obtendo média semanal de $1000,0 \pm 192,0 \mathrm{mg}$.

A oferta de fibras e o NdPCal\% também ultrapassaram a recomendação da legislação, apresentando-se excessivos e, portanto, inadequados. Desse modo, houve inadequação de proteínas, fibras e NdPCal\% em todos os dias (Tabela 2). 
Tabela 2 - Adequação nutricional (\%) dos sete cardápios do almoço de uma empresa do ramo hoteleiro inscrita no Programa de Alimentação do Trabalhador (PAT), 2019.

\begin{tabular}{lcc}
\hline \multicolumn{1}{c}{$\begin{array}{c}\text { Componentes } \\
\text { analisados }\end{array}$} & \multicolumn{2}{c}{$\begin{array}{c}\text { Dias de adequação aos } \\
\text { parâmetros } \\
\text { nutricionais do PAT* } \\
\text { n }\end{array}$} \\
\hline Valor energético (kcal) & 6 & 85,7 \\
Carboidratos (\%) & 6 & 85,7 \\
Proteínas (\%) & 0 & 0,0 \\
Gorduras totais (\%) & 2 & 28,6 \\
Gorduras saturadas (\%) & 7 & 100,0 \\
Sódio (mg) & 2 & 28,6 \\
Fibras (g) & 0 & 0,0 \\
NdPCal (\%) & 0 & 0,0 \\
\hline
\end{tabular}

*Para uma refeição principal, segundo o Ministério do Trabalho e do Emprego, 2006. PAT - Programa de Alimentação do Trabalhador.

Por outro lado, o percentual de gorduras saturadas esteve adequado em 100\% dos dias analisados (Tabela 2) e constatou-se a oferta de, pelo menos, uma porção de frutas e uma porção de legumes ou verduras em todos os cardápios do almoço.

\section{DISCUSSÃO}

Os cardápios avaliados apresentam, no geral, adequada oferta de calorias, carboidratos e gordura saturada, elevada oferta de proteína, sódio e fibras e baixa oferta de gordura total, em comparação aos valores obtidos aos parâmetros nutricionais estabelecidos pelo PAT.

O VET dos cardápios superou o valor máximo de 800 kcal. Contudo, como as recomendações nutricionais do PAT permitem o acréscimo de até $400 \mathrm{kcal}$ na refeição do almoço[ ${ }^{[1]}$, os valores encontrados no estudo ainda se encontraram dentro do proposto pelo programa. Esses achados são similares aos encontrados por Carneiro, Souza e Moura ${ }^{[6]}$, que, ao avaliarem a composição nutricional do almoço de uma UAN do estado de Goiás, encontraram uma variação energética de 874,4 a $1553,6 \mathrm{kcal}$.
Entretanto, há de se destacar que a atividade desempenhada pelos funcionários é de intensidade leve a moderada, de modo que o excedente calórico pode favorecer o desenvolvimento da obesidade e de outras doenças crônicas associadas à alimentação, afetando, assim, a produtividade, por dificuldades aos esforços e indisposição, por exemplo, e aumentando o absenteísmo no trabalho[7], inclusive por necessidades de consultas médicas.

Embora caiba ao nutricionista responsável técnico do estabelecimento avaliar o estado nutricional dos trabalhadores para verificar as suas necessidades energéticas e analisar se os cardápios devem ser ajustados ${ }^{[1]}$, os parâmetros nutricionais propostos pelo PAT carecem de revisão para nortear esse profissional, uma vez que já foram estipulados há quase 15 anos e que o perfil alimentar e nutricional da população vem se modificando continuamente. Além disso, esses parâmetros deveriam ser distintos quanto o tipo de atividade laboral desempenhado pelo trabalhador, já que a depender do nível de intensidade da atividade, exigir-se-á ou não maior demanda calórica[ ${ }^{[8]}$.

O percentual de carboidratos esteve, em média, dentro da recomendação. Isso é importante, uma vez que a ingestão elevada de carboidratos, principalmente àqueles de rápida absorção, favorece um desequilíbrio entre a oferta de macronutrientes, possibilitando o estabelecimento de hiperglicemia, resistência à insulina, hipertrigliceridemia e excesso de peso[?].

Por outro lado, o percentual de proteína esteve acima das recomendações do PAT para o almoço. Como o $\mathrm{NdPCal} \%$, que reflete a quantidade de proteínas líquidas da refeição também esteve elevado, infere-se que a presença desse nutriente foi oriunda principalmente de produtos cárneos. Destarte, a oferta de três opções proteicas nos cardápios em três dias da semana certamente possuiu uma contundente colaboração nos valores obtidos, pois os pratos proteicos não são porcionados e os comensais podem se servir de todas as opções.

Rocha et al.[10], em estudo realizado em uma unidade de alimentação e nutrição (UAN) hospitalar de São Paulo, obtiveram resultado semelhante a este, encontrando um percentual médio de $22,8 \%$ de 
proteína no cardápio semanal. Oro e Hautrive ${ }^{[11]}$, por sua vez, em pesquisa realizada em Santa Catarina, verificaram uma média de $21,2 \%$ de proteínas no almoço. Sabendo-se que o consumo excessivo de proteína traz riscos à saúde do comensal, pois aumenta o risco de lesão renal e, consequentemente, de doenças renais, o porcionamento de proteicos é estimulado[12].

Diferentemente de outros estudos ${ }^{[8,10]}$ que apontam a oferta excessiva de gorduras em seus cardápios, a presente pesquisa apresentou percentual lipídico abaixo das recomendações do PAT e o quantitativo de gordura saturada dentro dos parâmetros.

O fato de esse percentual lipídico estar abaixo da recomendação e o de gordura saturada adequado possui aspectos positivos, uma vez que inúmeras são as repercussões negativas da ingestão de gordura excessiva e, por isso, a importância do consumi-la dentro das recomendações. O tipo de gordura ingerida pode influenciar outros fatores de risco, como a resistência à insulina e o aumento da pressão arterial. O consumo de gordura saturada é classicamente relacionado à elevação do LDL-c plasmático e ao aumento de risco cardiovascular ${ }^{[13]}$.

Foi perceptível, no âmbito qualitativo, aspectos positivos na constituição do cardápio, a exemplo da oferta de frutas em todos os dias da semana como sobremesa, bem como a oferta de saladas diariamente. Duarte et al. ${ }^{[14]}$, diversamente, ao avaliarem a qualidade do almoço de uma UAN de uma empresa privada, segundo as recomendações do PAT, evidenciaram que não há a oferta de porção de frutas no almoço.

Cabe destacar que o PAT preconiza a oferta de pelo menos uma porção de frutas e uma porção de legumes ou verduras no almoço ${ }^{[1]}$. Esses alimentos constituem uma das fontes de vitaminas e minerais primordiais para a prevenção de deficiências de micronutrientes. Além de serem fontes de fibras, de nutrientes antioxidantes e de fornecerem pequena quantidade de calorias, são importantes para a prevenção do consumo excessivo de calorias e das doenças crônicas não transmissíveis, como diabetes e doenças cardiovasculares ${ }^{[15]}$. Possivelmente essa oferta propiciou o alto valor de fibras encontrado.
Inadequações quanto à oferta de fibras, assim como quanto à oferta de sódio também foram evidenciadas por Lagemann e Fassina[7], que, ao avaliarem a composição nutricional dos cardápios de uma UAN no Rio Grande do Sul encontraram uma média de 16,5 $\pm 2,0 \mathrm{~g}$ de fibras e de $2886,5 \pm 830,9 \mathrm{mg}$ de sódio; e por Duarte et al. [14], que encontraram média de $19,42 \pm 7,95 \mathrm{~g}$ de fibras e de

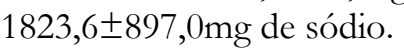

A oferta elevada de fibras, por um lado, pode ser considerada positiva, uma vez que grande parcela da população brasileira possui uma ingestão insuficiente de alimentos fontes de fibras ${ }^{[16]}$. Esses compostos estão associados a uma série de benefícios à saúde, bem como a redução dos níveis de glicose e lipídios séricos, além de auxiliar na melhoria do trânsito intestinal, no controle da pressão arterial e do peso corporal[ ${ }^{[17]}$.

Por outro lado, as fibras podem gerar efeitos característicos, tais como flatulência e distensão e comprometer a qualidade de vida do trabalhador no ambiente de trabalho, por isso a importância de consumi-las de maneira equilibrada. Além do mais, quando consumidas em excesso, as fibras podem diminuir a biodisponibilidade de alguns minerais, como, por exemplo, do ferro e do zinco, que no almoço estão presentes em maior quantidade ${ }^{[18]}$.

O quantitativo de sódio nos cardápios analisados ultrapassou o limite máximo do parâmetro estabelecido pelo programa para a refeição do almoço, que é de 720 a $960 \mathrm{mg}$. Tendo em vista o atual cenário epidemiológico de doenças crônicas não transmissíveis é importante a redução da oferta de sal/sódio, principalmente por se saber que o consumo de sal pela população brasileira encontra-se excessivo, em torno de 9,34g/dia, quase o dobro do recomendado pela Organização Mundial de Saúde $(5 \mathrm{~g} / \mathrm{dia})^{[19]}$.

Na UAN em questão, que adota o self-service, o colaborador possui total acesso ao quantitativo de alimentos que desejar consumir, de modo que o cálculo nutricional estimado na oferta pode não ser necessariamente $\mathrm{o}$ equivalente ao quantitativo consumido. Além disso, tem-se a disponibilidade do sal de mesa, cujo teor de sódio não foi computado nos cálculos realizados. Logo, a ingestão desse micronutriente, que fora ofertado em quantidade 
superior ao estabelecido pelo PAT, pode ser ainda maior ${ }^{[14]}$, acarretando prejuízos à saúde dos usuários.

Outro aspecto é que o sistema de gestão adotado se insere na modalidade de autogestão, no qual a elaboração do cardápio ocorre na própria empresa e pode tender a consentir às preferências dos comensais, em virtude da interação social entre eles, incluindo pratos mais calóricos e saborosos ${ }^{[8]}$.

Dessa forma, ações e práticas voltadas para a educação alimentar e nutricional são fundamentais no ambiente de trabalho, devendo ser realizadas de maneira contínua, para auxiliar os comensais a modificarem hábitos de vida que sejam prejudiciais à saúde e despertar neles a conscientização e a importância de uma alimentação saudável e adequada ${ }^{[12]}$.

O presente estudo se limitou a avaliar a composição nutricional dos cardápios ofertados e não a ingestão alimentar dos comensais ou a promoção de educação nutricional. Uma vez que o sistema adotado pela empresa é do tipo self-service, não se pode inferir que os nutrientes ofertados serão consumidos na quantidade prevista. Assim, estudos que avaliem o binômio oferta-ingestão tornam-se necessários para que seja possível saber a quantidade real de consumo do trabalhador, além de outros que avaliem a efetividade de atividades de educação nutricional nos hábitos alimentares dos trabalhadores.

\section{CONSIDERAÇÕES FINAIS}

No presente estudo evidenciou-se que, excetuando-se a oferta de calorias, carboidratos e a gordura saturada, a composição nutricional dos cardápios da empresa do ramo hoteleiro avaliada não se encontra dentro dos parâmetros nutricionais estabelecidos pelo PAT, demonstrando o descumprimento às normas estabelecidas pelo programa. Por outro lado, constatou-se a oferta diária de frutas, legumes e verduras em todos os cardápios.

Considerando que os parâmetros propostos visam à promoção da saúde do trabalhador, torna-se necessário que a empresa tenha atenção e revisão quanto aos cardápios ofertados, a fim de cumprir com os parâmetros estabelecidos de nutrientes, pois o PAT se insere como uma importante política pública de alimentação e nutrição, com vistas a segurança alimentar e nutricional. Dessa forma, é importante que haja a sensibilização dos envolvidos no programa, visando à compreensão da importância e da oportunidade que ele oferece no espaço de trabalho e de que a oferta de um cardápio adequado constitui uma estratégia para promover uma alimentação saudável e adequada.

\section{REFERÊNCIAS}

[1] Brasil. Portaria Interministerial no 66, de 25 de agosto de 2006. Altera os parâmetros nutricionais do Programa de Alimentação do Trabalhador - PAT. Diário Oficial da União: Brasília; 2006.

[2] Brasil. Ministério do Trabalho e do Emprego. Portaria $\mathrm{n} \div 3$, de 1을 de março de 2002. Baixa instruções sobre a execução do Programa de Alimentação do Trabalhador PAT. Diário Oficial da União: Brasília; 2002.

[3] Souza EB. Transição nutricional no Brasil: análise dos principais fatores. Cadernos UniFOA. 2017; 5(13): 49-53.

[4] Borjes LC, Lima JS. Programa de Alimentação do Trabalhador: avaliando o conhecimento por parte dos gestores administrativos e técnicos. DEMETRA: Alimentação, Nutrição \& Saúde. 2014; 9(1):107-119.

[5] Núcleo de Estudos e Pesquisas em Alimentação Universidade Estadual de Campinas (NEPAUNICAMP). Tabela brasileira de composição de alimentos (TACO). 4 ed rev e ampl. Campinas: NEPAUNICAMP; 2011. 161p.

[6] Carneiro NS, Moura CMA, Souza SCC. Avaliação do almoço servido em uma unidade de alimentação e nutrição, segundo os critérios do programa de alimentação do trabalhador. Alimentos e Nutrição Araraquara. 2013; 24(3): 361-365.

[7] Lagemann MD, Fassina P. Avaliação da composição nutricional de refeições oferecidas em uma Unidade de Alimentação e Nutrição. Caderno Pedagógico. 2015: 12(1): 36-45.

[8] Paula CLC, Dias JCR. Avaliação do consumo alimentar e perfil nutricional de colaboradores atendidos por uma Unidade de Alimentação e Nutrição (UAN). Revista Ciências Nutricionais Online. 2017: 1(1): 11-20.

[9] Sociedade Brasileira de Diabetes. Diretrizes da 
Sociedade Brasileira de Diabetes 2019-2020. Clannad Editora Científica: São Paulo. 2019. 491p.

[10] Rocha MP, Matias ACG, Spinelli MGN, Abreu ES. Adequação dos cardápios de uma unidade de alimentação em relação ao programa de alimentação do trabalhador. Revista Univap. 2014; 20 (35): 112-118.

[11] Oro GL, Hautrive TP. Avaliação do cardápio do almoço oferecido ̀̀ trabalhadores atendidos pelo Programa de Alimentação do Trabalhador. e-Scientia. 2015; 8(1): $1-7$.

[12] Oliveira CS, Alves FS. Educação nutricional em unidade de alimentação e nutrição, direcionada para consumo de pratos proteicos: um estudo de caso. Alimentos e Nutrição. 2008; 19 (4): 435-440.

[13] Faludi AA, Izar MCO, Saraiva JFK, Chacra APM, Bianco HT, Afiune Neto A, et al. Atualização da Diretriz Brasileira De Dislipidemias e Prevenção da Aterosclerose - 2017. Arquivos Brasileiros de Cardiologia. 2017; 109(1): $1-92$.

[14] Duarte MSL, Conceição LL, Castro LCV, Souza, ECG. Qualidade do almoço de trabalhadores segundo o Programa de Alimentação dos Trabalhadores e o Indice de Qualidade da Refeição. Segurança Alimentar e Nutricional. 2015; 22(1):654-661.

[15] Brasil. Ministério da Saúde. Secretaria de Atenção à Saúde, Departamento de Atenção Básica. Guia alimentar para a população brasileira. Brasília: Ministério da Saúde; 2014. 156 p.

[16] Louzada MLC, Martins APB, Canella DS, Baraldi LG, Levy RB, Claro RM, et al. Alimentos ultraprocessados e perfil nutricional da dieta no Brasil. Revista de Saúde Pública. 2015; 49(38): 1-11.

[17] Bernaud FSR, Rodrigues TC. Fibra alimentar: ingestão adequada e efeitos sobre a saúde do metabolismo. Arquivos Brasileiros de Endocrinologia \& Metabologia. 2013; 57 (6): 397-405.

[18] Machado WM, Capelari SM. Avaliação da eficácia e do grau de adesão ao uso prolongado de fibra dietética no tratamento da constipação intestinal funcional. Revista de Nutrição. 2010; 23 (2): 231-238.

[19] Malta DC, Machado IE, Pate A, Pereira CA, Jaime PC, Szwarcwald CL , et al. Estimativa do consumo de sal pela população brasileira: resultado da Pesquisa Nacional de Saúde 2013. Revista Brasileira de Epidemiologia. 2019; 22 (suppl 2): 1-14. 